\title{
Atitude crítica de idosos sobre atividade física
}

CDD. 20.ed. 613.7

796.018
Tiemi OKIMURA-KERR* Silene Sumire OKUMA**
*Centro Universitário Sant'Anna.

${ }^{* *}$ Escola de Educação Física e Esporte,

Universidade de São Paulo.

\section{Resumo}

0 objetivo deste estudo foi analisar a atitude crítica em relação à atividade física dos idosos do Programa Autonomia para Atividade Física. Participaram do estudo 18 sujeitos que responderam duas questões abertas após vivência das seguintes aulas: atividade rítmica, yoga, dança circular, tai chi chuan, dança de salão, aerobox e atividades para idosos orientadas através de vídeo. A análise qualitativa resultou em duas categorias de respostas: reflexão sobre necessidades pessoais e reconhecimento de inadequações nas atividades propostas. Dessas respostas, $43 \%$ indicam reflexão crítica e 37\% apontam inadequações. Os resultados sugerem que a maioria das respostas não demonstra atitude crítica em relação às aulas vivenciadas. Entretanto, uma das limitações deste estudo foi a dificuldade dos alunos no procedimento da escrita, indicando a necessidade de criar outras estratégias para avaliar a população idosa que é heterogênea em termos de escolarização e experiências de vida.

UnITERMos: Autonomia para atividade física; Idosos; Educação permanente.

\section{Introdução}

O processo de envelhecimento do ser humano é influenciado fundamentalmente por fatores genéticos e culturais (BALTES, 1987). A dimensão genética é caracterizada por fatores biológicos, cujo ponto central éo declínio; entretanto, o conhecimento e a cultura podem atuar positivamente sobre a dimensão sócio-cultural.

Relacionados às limitaçôes biológicas, os déficits físico-motores e suas consequências foram evidenciados por vários pesquisadores (AKIMA, KANO, NomOto, Ishizu, Okada, Oishi, Katsuta \& Kuna, 2001; ChodzKo-ZajKo, 1998), porém estudos (Brandon, Boyette, GaAsch \& Lloyd, 2000; Guido, Lima, Benford, Leite, Pereira \& Oliveira, 2010; O’Neill, Thayer, Taylor, Dzialoszynski \& Noble, 2000; TAKKInen, SuUtama \& RUOPpila, 2001) sustentam a hipótese dos efeitos positivos da atividade física no processo de envelhecimento, o que indica a plasticidade capacidade adaptativa dos idosos. Esses estudos contribuem para que a importância da atividade física seja reconhecida internacionalmente como estratégia para a promoção de um estilo de vida saudável, sendo prioritária para a população idosa, como aponta a Organização Mundial de Saúde (OMS, 2001).

Entretanto, TeIXEIRA (2004) apresenta a carência de disciplinas que estudem a população idosa nas grades curriculares dos cursos de preparação profissional em Educação Física como causa dos serviços com qualidade duvidosa. Ele acrescenta que a maioria desses cursos busca habilitar os profissionais em licenciatura com as disciplinas focadas em grupos etários mais jovens. Os resultados das pesquisas encontradas pelo autor, mesmo em áreas mais tradicionais como a medicina e enfermagem, indicam deficiências na formação desses profissionais para atuar com idosos.

Além dos profissionais desconhecerem as características dessa faixa etária, eles desconsideram os objetivos individuais dos idosos, como denunciou FARIA JUNIOR (2000). Há, por exemplo, o equívoco de se subestimar o potencial do idoso, oferecendolhe atividades com intensidade que estimulem insuficientemente suas capacidades físicas, não levando aos benefícios fisiológicos esperados, pois muitos profissionais desconsideram um dos princípios de treinamento que é o da sobrecarga. Para MCMurdo (1999), a falta de conhecimento e habilidade dos profissionais da saúde para prescrever atividade física ocasiona um medo exagerado quanto aos seus riscos. Em outro extremo, há programas que colocam em risco a integridade física dos idosos quando, por 
exemplo, propõem atividades com posturas inadequadas que podem provocar ou exacerbar alterações músculo-articulares degenerativas por movimentos repetitivos realizados incorretamente.

Nessas condiçôes de serviços, torna-se fundamental que o aluno tenha uma postura crítica em relação às atividades propostas pelo mercado de atividade física. Para tal, é importante que ele saiba refletir se o exercício oferecido contempla suas necessidades pessoais e se não prejudica sua saúde. O presente estudo tem como objetivo analisar o processo de ensino e aprendizagem dessa atitude crítica em idosos de um programa de educação física.

\section{Promoção da saúde, autonomia e atitude crítica}

Segundo FARINATTi (2000), ocorre uma mudança paradigmática que evita as relaçôes de causa-efeito típicas da abordagem biomédica e realça a natureza plurifatorial da saúde, enfatizando suas relações com a autonomia individual e coletiva. $\mathrm{O}$ novo paradigma ficou evidenciado na definição de promoção da saúde oriunda da Primeira Conferência Internacional sobre o tema realizada pela OMS (2001, p.19): processo de capacitação da comunidade para atuar na melhora de sua qualidade de vida e saúde, incluindo uma maior participação no controle desse processo. (...) os indivíduos e grupos devem saber identificar aspirações, satisfazer necessidades e modificar favoravelmente o ambiente.

Uma das bases para capacitar as pessoas a realizarem seu potencial de saúde inclui o acesso à informação e à oportunidades que lhes permitam fazer escolhas por uma vida sadia (OMS, 2001). De acordo com FARINATTI (2002), a importância das escolhas esclarecidas está presente nas discussões sobre as relações entre autonomia e qualidade de vida. Para o autor, a autonomia corresponde a um direito que pressupóe o respeito aos seus valores, vontades e papel social. SEEDHOUSE e CRIBB (1989) também consideram que um dos temas centrais na concepção de saúde que valoriza a pessoa é a autonomia. Para eles, ser autônomo significa ser capaz de compreender o meio e as circunstâncias, fazer escolhas racionais e agir de acordo com essas escolhas.

$\mathrm{Na}$ área da educação, FreIrE (1996) afirma que é a partir da experiência das decisões que se vai constituindo a autonomia, através da construção ou produção do conhecimento que implica na capacidade crítica de comparar, perguntar, "tomar distância" do objeto, observá-lo, delimitá-lo, cindi-lo, cercá-lo ou fazer sua aproximação metódica. Segundo SARABIA (1998), a organização das crenças, das reações ou da capacidade de crítica está presentes em todas as atitudes, pois envolvem juízo de valor, o que requer a compreensão consciente do objeto, pessoa ou situação.

Apesar de sua relevância, nota-se uma carência de estudos sobre este tema na área da Educação Física.
No campo da Psicologia, Denney (1995) mede a capacidade de pensamento crítico presente em adultos, através da solução de problemas práticos e da avaliação de suas declarações. A autora encontrou que o nível de escolarização foi significativamente relacionado a escores do pensamento crítico em idosos.

A ausência de pesquisas sobre a atitude crítica de idosos fez recorrer aos estudos sobre o processo educacional dessa faixa etária no âmbito mais geral.

\section{Programa de ensino para idosos}

Em sua revisão de literatura, FARIA JUNIOR (2000) encontrou poucos estudos sobre o ensino voltado para idosos e conclui que esse tema não é destacado, mesmo no contexto internacional da educação. A maior parte das pesquisas encontradas pelo autor versava sobre estratégias de ensino, a mesma temática das publicações encontradas na revisão de literatura para o presente estudo (CLARCK \& Heller, 1997; Jones \& BAYEN, 1998; SPigner-Littles \& Anderson, 1999; Strom, Strom, Fournet \& Strom, 1997; TwitChel, CHERry \& TrotT, 1996). Dentre elas, destaca-se o estudo de Spigner-LitTles e ANDERSON (1999), que indica caminhos para o desenvolvimento e implantação de uma pedagogia efetiva para idosos com base no paradigma construtivista.

No contexto brasileiro, o estudo de Santos de SÁ (1999) verificou as condições de aprendizado do uso do computador pelos idosos. A alta escolarização foi indicada como um dos fatores que facilitou a aprendizagem enquanto a memória e atenção foram indicadas como fatores dificultadores. Já, o estudo etnográfico de Pizzolato (1995) teve o objetivo de compreender o processo de ensino e aprendizagem da língua estrangeira (inglês) pelos idosos. A análise dos dados revelou que eles buscavam contato social, apresentavam acuidade auditiva e capacidade de memória diminuídas e tinham necessidade de externar suas emoçôes e problemas pessoais. Isso evidencia a importância do elemento empatia entre professor-aluno e leva o professor a refletir sobre os reais objetivos e interesses dos alunos. 
Como visto, os tipos de pesquisa sobre aprendizagem são bastante heterogêneos, pois provém de propostas com diferentes concepções de ensino e aprendizagem. Segundo FARIa Junior

\section{Método}

\section{Pesquisa}

Esta é uma pesquisa qualitativa com características metodológicas apontadas por BOGDAN e BIKLEN (1997) em que a fonte direta dos dados é o ambiente natural, é descritiva, tem interesse pelo processo e não pelo produto e análise dos dados é indutiva, não havendo hipóteses a serem confirmadas.

\section{Contexto: Programa para Autonomia da Atividade Física (PAAF)}

O PAAF, ambiente de pesquisa deste estudo, é um programa de educação permanente que tem como preceito teórico o modelo da velhice bem-sucedida (BAltes \& Baltes, 1991) e defende a capacitação das pessoas para continuar a aprender durante toda vida. Por esta razão, o programa tem a preocupação de ensinar idosos a realizar atividade física como estratégia de autocuidado frente ao processo de envelhecimento. O PAAF tem como objetivo a realização autônoma da atividade física, que pode ser praticada sem supervisão de um profissional ou num programa oferecido pelo mercado.

Sua proposta de ensino se fundamenta na concepção construtivista apontada por Coll, Pozo, SARABIA e VAlis (1998), em que os alunos e os professores devem assumir um papel ativo no processo de ensino e aprendizagem. Com base nessa concepção, os conteúdos são estruturados em conhecimentos conceituais (o que o aluno deve saber), procedimentais (o que ele deve saber fazer) e atitudinais (o que ele deve ser). As unidades temáticas que compóem os conteúdos do PAAF são: sistema cardiovascularrespiratório e capacidade aeróbia, sistema muscular e força, sistema articular e flexibilidade e sistema nervoso e capacidades neuromotoras (agilidade, equilíbrio, tempo de reação e tempo de movimento). Estas unidades são desenvolvidas por meio de atividades teóricas e, predominantemente, por práticas motoras específicas a cada uma delas.

A duração do PAAF foi de 16 meses, com duas aulas semanais de 120 minutos cada. O programa foi dividido em cinco fases:
(2000), aprender é um termo que compreende diversas classes de comportamento individual e sua ocorrência em idades avançadas é um assunto pouco estudado e eivado de complexidade.

- Fase 1: aprendizagem de fatos e conceitos sobre os sistemas do corpo, seu processo de envelhecimento e sua relação com a atividade física.

- Fase 2: reforço da aprendizagem dos conteúdos conceituais e generalização dos princípios da prescrição de treinamento.

- Fase 3: aprendizagem da atitude crítica em relação à programas de atividade física.

- Fase 4: criação de exercícios para atender as necessidades pessoais.

- Fase 5: elaboração de um programa de atividade física em diferentes espaços.

A fase 3, aqui estudada, foi composta por seis aulas ministradas por professores convidados, que desenvolveram diferentes tipos de atividade física (atividades rítmicas, yoga, dança de salão, "tai chi chuan", dança circular, aerobox), além de uma aula orientada através de um vídeo comercial que propunha atividade física para idosos.

Ao final de cada uma dessas aulas, os alunos responderam as seguintes questões abertas : 1) "Esse tipo de atividade supriu suas necessidades físicas, funcionais (capacidade de realizar as atividades da vida diária) e possíveis limitações de saúde? Porque?”; 2) "Durante o desenvolvimento da aula, você considera que houve algum movimento inadequado à sua condição física? Em caso afirmativo, você poderia citar qual foi este momento?”.

No início da aula seguinte eram realizados diálogos e as discussões sobre as respostas das duas questões em grupo que, segundo SARABIA (1998), são momentos ideais para instigar a reflexão, o tratamento e a reelaboração pessoal das informações, de modo que os alunos elaborem argumentos e a experiência vivenciada na aula anterior tenha sentido. Segundo Lima (2001), nos programas de educação para idosos, é fundamental uma pedagogia em que o diálogo seja uma estratégia para respeitar o saber que o idoso traz de sua vida, chamando-o a pensar, a fazer uma nova leitura de sua realidade, a ser consciente, a ser sujeito.

Um dos pressupostos desses momentos de diálogo é a função do professor em mediar, coordenar e problematizar os conceitos apresentados pelos alunos 
(GARRIDO, 2001). Dessa forma, o professor favorece a autonomia intelectual do aluno, fazendo-o pensar e o prepara para atuar de forma competente, criativa e crítica como cidadão.

A opção em analisar as tarefas se deu, pois elas permitem que os alunos elaborem seus próprios argumentos e expressem suas atitudes em relação a cada uma das atividades experienciadas. Como afirma SARABIA (1998), as atitudes são construtos hipotéticos, não sendo diretamente observáveis, necessitando ser inferidos a partir das respostas dos sujeitos. Assim, a realização da tarefa permitiria que os alunos utilizassem os conhecimentos ensinados no PAAF, como os benefícios da ativação dos sistemas do corpo e os princípios da prescrição de treinamento das capacidades físicas e execução correta dos exercícios, para refletir sobre o alcance de suas necessidades pessoais e reconhecimento de movimentos inadequados. Desta forma, teriam a oportunidade de aprender procedimentos cognitivos para a atitude crítica, como os sugeridos por FREIRE (1996): observar a atividade física, questionar sobre sua adequação, comparar com suas necessidades pessoais e discernir sobre o que é ou não apropriado para que possa julgar se devem incluir a atividade no seu cotidiano.

\section{Os alunos}

Fizeram parte desse estudo os alunos que participaram de, no mínimo, cinco do total de sete aulas da fase 3 do PAAF, o que totalizou 18 idosos, sendo quatro homens e 14 mulheres, com idade média de $65 \pm 5,25$ anos (faixa etária entre 60 a 81 anos). Quanto à escolarização, 55\% concluíram o ensino médio ou superior e $45 \%$ concluíram o ensino fundamental. Em relação à profissão exercida, havia quatro professoras, três costureiras, duas secretárias, dois comerciantes, uma atendente de enfermagem, um encanador, uma funcionária pública, um administrador, uma economista, um policial militar e uma dona de casa. A maioria dos alunos (67\%) declarou ter praticado atividade física (caminhada, natação, dança, alongamento, hidroginástica, yoga, esportes ou brincadeiras infantis) desde a idade adulta, 11\% apenas na adolescência e $22 \%$ nunca a praticou.

Ao ingressarem no PAAF, os alunos estavam cientes de que era um programa de extensão e pesquisa, assinando um consentimento livre e esclarecido para utilização do material produzido por eles. Para que suas identidades fossem mantidas em sigilo, os nomes de todos os alunos foram substituídos por códigos compostos pela letra "A" seguida por um número de $1 \mathrm{a} 18$.

\section{Análise das respostas na avaliação da aprendizagem}

As respostas dos alunos foram analisadas de acordo com as recomendaçōes de análise qualitativa sugeridas por BOGDAN e BiKLEN (1997) e resultou em duas categorias: 1) reflexão sobre necessidades pessoais, subdividida em presença de reflexão e ausência de reflexão; 2) reconhecimento de inadequações nas atividades propostas, também subdividida em alunos que reconheceram e alunos que não conseguiram reconhecê-las.

\section{Alunos que refletem sobre suas necessidades pessoais}

A primeira categoria demonstra a capacidade do aluno em identificar o sistema do corpo ativado e os decorrentes benefícios fisiológicos, de modo que pudessem compará-los a seus objetivos pessoais. Isso porque, como apontado por RESNICK (2001), o conhecimento sobre os benefícios da atividade física é um dos fatores associados à sua adesão, portanto, considera-se que refletir sobre a necessidade de treinar cada capacidade física influencia na decisão do aluno de continuar a praticá-la, após seu egresso do PAAF.

A primeira questão focava a dimensão física dos benefícios da atividade física baseada nos conhecimentos sobre seus efeitos nas suas capacidades físicas, funcionais e possíveis limitaçôes de saúde, conteúdo ensinado no PAAF. Porém, ao analisar as respostas, pôde-se observar que os alunos refletiam sobre suas necessidades com base em preferências pessoais, percepção de inadequaçóes para si e reconhecimento de que a atividade física atende parcialmente suas necessidades físicas ou supre outras necessidades.

Como pode ser observado na TABELA $1, \operatorname{dos} 43 \%$ de respostas que indicam a capacidade do aluno em refletir sobre suas necessidades, $13 \%$ foi baseada nas preferências pessoais, isto é, no seu apreço pela atividade realizada. SARABIA (1998) afirma que nem sempre as pessoas agem buscando a máxima racionalidade nos seus pensamentos e ações, pois as atitudes e suas expressões não são construções lógicas e perfeitamente coerentes. Isso pode explicar as respostas baseadas em gostos, apontando que a eficiência na ativação dos sistemas do corpo não foi o critério prioritário para responder à questão. $\mathrm{O}$ aluno $\mathrm{A} 8$, por exemplo, demonstrou que não aprecia atividade rítmica: "prefiro mais atividades de flexibilidade e força", assim como A5: "forçosamente não irei realizar essa dança. Não gosto de dançar, não sei dançar. Vou escolher outra atividade (...) necessária à minha condição física". 
Essas respostas vão ao encontro do que afirma WANKEL (1997), citado por VELARDI (2003), quando diz que o gosto pessoal é uma das variáveis para a prática de determinado comportamento. Estimular a reflexão sobre a preferência pessoal dos alunos pode ajudá-los a escolher a atividade física mais adequada para si, visto que é um dos critérios para a sua seleção. Esses exemplos também reforçam a importância de se considerar o componente afetivo na elaboração de programas de atividade física. Spigner-LitTles e ANDERSON (1999) destacam que o reconhecimento e inclusão de conteúdos atitudinais que levam em consideração as emoções dos idosos é um dos elementos essenciais numa pedagogia efetiva para eles. WHALEY e EBBECK (1997) enfatizam o divertimento e o prazer como principais pontos para estruturar programas para essa população a fim de aumentar o seu nível de adesão à atividade física. Isso é relevante quando se verifica que, atualmente, pouco se sabe sobre as preferências dos idosos quanto à atividade física, como relatam Ecclestone, Myers e PAterson (1998).

TABELA 1 - Reflexão dos alunos sobre as necessidades pessoais.

\begin{tabular}{llc}
\hline \multicolumn{1}{c}{ Distribuição das respostas } & $\%$ \\
\hline Presença de reflexão & \multicolumn{1}{c}{ \% } & 43 \\
& Preferências pessoais & 13 \\
& Supre necessidades em outras dimensões & 10 \\
& Supre parcialmente as capacidades físicas & 8 \\
& Não supre, reconhece inadequações & 8 \\
& Supre necessidades da vida diária & 4 \\
\hline \multirow{2}{*}{ Ausência de reflexão } & & 57 \\
& Não responde & 21 \\
& Repete enunciado & 21 \\
& Resposta genérica & 9 \\
& Dificuldade em se expressar & 3 \\
& Insuficiente para avaliar & 3 \\
\hline
\end{tabular}

Em 10\% das respostas que contemplam reflexões, os alunos apontaram a predominância de outras necessidades atendidas pelas atividades realizadas. Possivelmente, eles atribuíram outros significados para a prática de atividade física, além dos benefícios fisiológicos enfatizados na maioria dos programas para justificar a sua importância. ANDREOTTI e OKUMA (2003) já afirmaram que o conhecimento sobre esses tipos de benefícios é insuficiente para assegurar a participação das pessoas nos programas. Como apontam SolÉ e Coll (1997), é a percepção de uma necessidade a ser preenchida que dá sentido para a aprendizagem significativa, ou seja, nem sempre as razões apontadas pelo professor como objetivos na dimensão física é o que mobilizará o aluno a se interessar pela atividade física, mas a sua percepção de que ela supre uma necessidade pessoal, seja qual for a dimensão.

Por exemplo, A18 declarou que a aula de dança de salão "torna as atividades mais prazerosas. Aproxima pessoas, liberta tensōes”. Essa fala corrobora os resultados do estudo de ECHEVERry, TABORDA e Gómez (2002) no qual os idosos praticantes de dança de salão sentiram bem-estar, pois esqueceram momentaneamente as preocupaçóes sociais e familiares. Para eles, a manutenção das relações com outras pessoas permite reconhecer-se e ser reconhecido pelos demais como ser social dentro do pequeno coletivo com o qual se relaciona. $\mathrm{O}$ mesmo pôde ser observado em outros contextos educacionais, como no programa de ensino da língua estrangeira analisado por Pizzolato (1995).

Ainda, outra aluna apontou os efeitos do "tai chi chuan" em sua ansiedade: "A meu ver, tal atividade seria excelente (...) ela me levaria a dominar mais a ansiedade e levar meu dia-a-dia de maneira mais calma” (A14). Nessa mesma dimensão, A13 atribuiu benefícios mais genéricos à aula de yoga: "Pelos benefícios da mente, do corpo, etc. Equilíbrio corpo-mente". Apesar dessa fala genérica sobre os benefícios da atividade física estar presente no jargão popular, Scully, Kremer, Meade, Graham e DudGEON (1998) alertam que não é qualquer atividade que pode ser considerada panacéia ou veneno para todos os componentes psicológicos.

Também foram consideradas como reflexão sobre a dimensão física dos benefícios da atividade física as respostas que indicavam que as atividades não atendiam 
ou atendiam parcialmente as necessidades pessoais dos idosos ( $8 \%$ cada). Um exemplo é a resposta de A17 quando diz que a aula de yoga supriu "complementarmente a outras atividades como as predominantemente cardiovascular e capacidade aeróbia e muscular e força”. Como a aluna já praticava yoga antes de ingressar no PAAF, provavelmente, ela já tinha refletido sobre suas necessidades pessoais relacionados aos benefícios desse tipo de atividade. Segundo Zabala (1998), no processo de aprendizagem, o aluno compara seus antigos conhecimentos aos novos e identifica semelhanças e diferenças, integrando-os a seus esquemas de pensamento. Todos os alunos que refletiram sobre suas necessidades pessoais, na maior parte de suas respostas, foram praticantes de atividade física (A5, A7, A8, A13, A14, A15 e A18). Portanto, os professores têm o desafio de resgatar o conhecimento prévio dos alunos ao longo do processo de ensino.

Mais uma vez A17 demonstrou reflexão crítica quando declarou que a atividade rítmica atende suas necessidades: "parcialmente, porque preciso também de atividades com força muscular". Pode-se observar a preocupação dos alunos em otimizar suas capacidades físicas, complementando as atividades propostas. Porém, houve a ênfase nas atividades de força e capacidade aeróbia, que pode ser em decorrência da maior difusão sobre os benefícios fisiológicos dessas capacidades físicas pela mídia e pelos profissionais da área de saúde. Como aponta FarinatTi (2000), a possibilidade de realizar aspirações e satisfazer necessidades potencializa a autonomia do idoso, e o primeiro passo para tal é ter consciência delas. Cabe ao profissional de EF ampliar o repertório de atividade física para que eles possam otimizar sua capacidade de escolha optando pela mais adequada para si.

Outras respostas que contemplam a reflexão crítica dos alunos sobre suas potencialidades e limitações foram as que eles reconheciam exercícios inadequados para os problemas pessoais. Em 8\% delas os alunos indicaram que a atividade não era apropriada para as suas condições físicas ou limitações de saúde, como ilustrado pelas falas de A5: “(...) tem muita rodada, tive cuidado por causa da labirintite" e de A9: "(...) achei os exercícios bem pesados que fizeram doer a coluna e a artrose dos joelhos".

Finalmente, as respostas que demonstravam reflexão crítica com menor frequência foram aquelas em que o aluno considerou que a atividade supria suas necessidades pessoais, particularmente as capacidades funcionais (4\%). Segundo McMurdo (1999), os idosos se motivam a permanecem ativos quando acreditam que a atividade física trará benefícios para sua saúde e preservará sua capacidade funcional. Algumas falas reforçam essa suposição: "para a vida prática tal atividade também é boa, pois agilizará tudo o que eu for executar (...), como por exemplo atravessar uma rua" (A15) e "nas atividades diárias a concentração, o equilíbrio e memorização são sempre necessárias, por exemplo: cozinhar, arrumar, etc" (A16).

Ao associar os benefícios da atividade física às atividades cotidianas, além de demonstrar a aplicação dos conhecimentos aprendidos no PAAF, esses alunos, possivelmente, atribuíram um significado para a atividade física. Segundo VeLARDI (2003), o ensino de atitudes e valores, através da atribuição de significado, é mais eficiente para que a pessoa adote um comportamento ativo do que apenas o conhecimento de que algo é bom para a saúde. Assim, reforça-se a necessidade de estratégias de ensino que otimizem a atribuição de significado. ОкUма (2002) faz uma crítica aos modelos de programas de atividade física que utilizam estratégias de intervenção cujo estimulo é externo à pessoa, pois tentam conduzi-la a alcançar aquilo que é considerado bom pela ciência e pelos profissionais, e não necessariamente por ela. Para a autora, o ensino da atividade física é estratégia para envelhecer bem porque viabiliza que a pessoa aprenda a praticá-la corretamente, além de constituir uma possibilidade de educação permanente.

\section{Alunos que não refletiram sobre suas necessidades pessoais}

Observando-se a TABELA 1, verifica-se que 57\% das respostas indicam que os alunos não refletiram sobre suas necessidades pessoais, seja porque não responderam (21\%), seja porque repetiram o enunciado da pergunta $(21 \%)$. Foi considerada como não respondida as respostas que estavam em branco ou quando o aluno não justificava se a atividade física experienciada na aula supria suas necessidades físicas, funcionais e limitaçōes de saúde, ou seja, se as respostas continham apenas "sim" ou "não". As respostas que repetiam o enunciado da pergunta podem ser ilustradas pelas falas de A9: "sim, supre as necessidades da vida diária" e A2: "sim, porque me ajuda nas atividades do lar", indicando que ambas remeteram-se às mesmas palavras ou à sinônimos presentes no enunciado da pergunta. Apesar de atribuírem um significado às atividades do aerobox no cotidiano, por exemplo, não explicitaram quais são as situações da vida beneficiadas por essa atividade.

Ao analisar as características desses alunos, verificouse que são os que apresentaram os menores níveis de escolarização, tendo estudado no máximo até o ensino 
fundamental. Uma explicação pode ser a dificuldade deles em se expressar por meio da linguagem escrita ou de compreender a pergunta. Em contrapartida, os alunos que refletiram sobre suas necessidades na maior parte das respostas tinham o ensino médio ou superior concluído. No trabalho de educação de adultos, Moura (1999) considera que um dos fatores para o aluno não executar a atividade proposta é a demanda por um tipo de elaboração cognitiva desconhecida por ele. Assim, pressupóe-se que os procedimentos cognitivos de identificação, comparação e julgamento exigidos nas tarefas possivelmente significaram uma barreira para os alunos com baixa escolarização.

Esses resultados corroboram os achados de SANTOS DE SÁ (1999) em que a escolarização facilitou o aprendizado dos alunos com alta escolaridade, e os de DENNEY (1995) que mostram adultos com maior escolarização mais aptos a desenvolver atividades com estimulação intelectual, tendo menor declínio cognitivo.

A análise da TABELA 1 também revela que 9\% dos alunos tiveram dificuldades em se expressar, pois escreveram palavras ou expressões genéricas, como a de A3: "porque estimula todo o corpo". Nota-se que não há referência a nenhum benefício específico da atividade experimentada que, no caso, foi a dança circular. Outra resposta que demonstrou a mesma dificuldade foi de A1 que a declarou em três atividades e, em uma delas, acrescentou: “... desculpe por não dar mais explicações”. Tal fala, além de indicar consciência de sua dificuldade em se expressar, mostra sua preocupação em não corresponder a uma habilidade esperada pelos professores. Evidenciase, então, a importância de estratégias de ensino e avaliação que não originem constrangimentos pelo "não saber" responder às tarefas. Como indica SMOLE (2001), o desejo de comprovação do saber através da escrita contribui para que a responsabilidade do sucesso ou fracasso recaia mais diretamente sobre o aluno, que é prejudicado em sua avaliação quando não consegue se expressar do modo esperado ou não domina a escrita completamente.

Finalizando, observa-se que houve 3\% de respostas em que eles consideraram algumas experiências insuficientes para responder com precisão às perguntas. A15 declarou que "é necessário conhecer melhor "tai-chi" para a certeza (se supre ou não suas necessidades)". Observa-se coerência na sua resposta, pois o tempo de prática nessa aula dificultou identificar com clareza a capacidade física estimulada, visto que o instrutor discorreu sobre a filosofia do "tai chi chuan" na sua maior parte. Apesar da vivência ser insuficiente para avaliar se a atividade atende as necessidades físicas, os alunos poderiam ter justificado com argumentos em outras dimensões, que pareciam ser prioritárias no "tai chi chuan". A13 apontou o mesmo dizendo que "foi pouco tempo. Gostaria de conhecer melhor para, de fato, saber se essas atividades me auxiliarão na vida diária”. Essa fala indica, também, que as aulas dessa fase do PAAF foram estímulo para os alunos quererem conhecer outros programas de atividade física.

Um dos propósitos em oferecer diferentes experiências de atividade física para os idosos foi ensiná-los a refletir se suas necessidades pessoais são atendidas, tanto as fisiológicas, como as afetivas ou sociais, de modo que as futuras escolhas de atividade física sejam feitas de forma mais esclarecida e consciente. Essa reflexão é fundamental pois, no atual momento, a preparação profissional para atuar com idosos ainda está se consolidando. Segundo Freire e Sommerhalder (2000), muitas vezes os profissionais encaram a velhice de maneira preconceituosa e lidam com os idosos com base naquilo que pensam ser importante para eles, sem pesquisar quais são suas reais necessidades, sem lhes perguntar o que pensam e desejam. Para as autoras, ainda há muitos aspectos a serem investigados para que se desenvolvam projetos adequados às necessidades dos idosos. Whaley e EBBECK (1997) sugerem a estratégia de perguntar aos idosos o que eles consideram apropriado e potencialmente benéfico para si, associado ao aumento da variedade e flexibilidade na programação, como também sugere SPIGNER-LITTLES e ANDERSON (1999).

\section{Alunos que reconheceram o que é inadequado para si}

Considera-se fundamental que os idosos tomem os devidos cuidados ao exercitar-se ou saibam adaptar as atividades propostas pelo mercado de atividade física às suas condições físicas e funcionais, ou ainda às possíveis limitações de saúde. Assim, na fase 3 do PAAF objetivou-se que os alunos reconhecessem nas diferentes atividades experimentadas os movimentos inadequados para suas condições pessoais.

Foram consideradas nesta subcategoria todas as respostas que indicaram qualquer tipo de inadequação, tanto de execução de movimentos como dos princípios de prescrição de treinamento. Como pode ser observada na TABELA 2, essa subcategoria totaliza 39\% das respostas, sendo que em 21\% delas os alunos apontaram exemplos de movimentos inadequados para si. 
TABELA 2 -Reconhecimento dos alunos sobre inadequações da atividade física para si.

\begin{tabular}{llc}
\hline \multicolumn{1}{c}{ Distribuição das respostas } & \% \\
\hline Reconhece & \multicolumn{1}{c}{39} \\
& Exemplifica & 21 \\
& Aponta outras inadequações & 16 \\
& Expressa insatisfação com a aula & 2 \\
\hline Não reconhece & & 61 \\
& Não responde & 52 \\
& Expressa aceitação com a aula & 8 \\
& Dificuldade em expressar-se & 1 \\
\hline
\end{tabular}

A grande incidência de respostas similares que se referiram à um mesmo movimento impróprio pode ser indicativos da presença de inadequações oriundas da própria atividade ou da forma com que foi conduzida, como por exemplo o chute durante a aula de aerobox. Esse movimento provocou desconforto em sete alunos (39\%), como verificado na fala de A15 ("sim, os chutes (...), senti um pouco a região lombar") e de A18 ("na parte de chutar senti muita dor na coluna”). Segundo Salles e Hovell (1990) citados em Andreotti (2001), a sensação de desconforto é um fator de desistência da atividade física, portanto, os profissionais de EF devem estar atentos para que seja evitada.

A17 considerou o chute como movimento de difícil execução ("Inadequado não, mas como já disse, tive dificuldade nos chutes, principalmente quanto ao equilíbrio.") e A12 relatou desconforto, mas soube adaptar-se à atividade sob orientação da professora ("Doeu o joelho durante o chute, mas a professora disse que era para chutar devagar, então não doeu”). Isso reforça a necessidade de que os alunos estejam conscientes de que nem sempre os professores conseguem perceber suas dificuldades ou desconforto quando eles não os manifestam. É nesse sentido que o ensino da atitude crítica é fundamental para que o aluno seja capaz de questionar a adequação da atividade física proposta, assim como, posicionar-se quanto às suas percepções sobre a atividade realizada.

Outro movimento bastante referido como difícil ou desconfortável foi a posição sentada durante a aula de "tai chi chuan", como apontado por A9: “(...) não consigo sentar sem encosto, tive dor nas coxas, virilha, fiz muita força para ficar ereta, tive um mal estar repentino e transpirei muito no pescoço e cabeça, desmanchei a pose e melhorei” e A17: “(...) para mim foi ruim porque não consigo cruzar as pernas e, para ficar na posição, forcei muito a coluna e não consegui ficar relaxada". Pode-se perceber que A9 soube fazer adaptações em seu corpo, o que pode favorecer a execução de uma atividade sem risco de lesão e de forma confortável. Porém, a melhor solução para sentir mais conforto na posição sentada com as pernas cruzadas é através da utilização de recursos como o uso de materiais auxiliares, e não somente "desmanchar a pose", ou seja, modificar posiçôes. É evidente a importância do professor estar atento às necessidades dos alunos, pois cabe a ele fazer as adaptações necessárias para que as limitações, assim como as potencialidades dos alunos, sejam respeitadas. Segundo OKUма (2002), um ponto fundamental para o desenvolvimento de comportamentos e atitudes positivas frente à atividade física é o respeito às necessidades reais e pessoais dos alunos, geralmente pouco consideradas. Para a autora, são necessários modelos educacionais com a constante preocupação em adaptar as atividades à realidade das pessoas, de modo a ampliarem e reforçarem o valor daquilo que lhes é ensinado.

Os argumentos utilizados pelas alunas para identificar movimentos inadequados basearam-se no reconhecimento de suas respostas corporais, parecendo não fazer uso de critérios objetivos ensinados no PAAF, como a sobrecarga que a hiperflexão de joelhos exerce nas articulações. Portanto, possivelmente, as alunas não utilizaram o conhecimento científico que permitiria generalizações e contribuiria para sua maior autonomia, pois, como aponta FREIRE (1996), para o seu alcance é necessária a superação do conhecimento do senso comum pelo científico.

As respostas de alunos que reconheceram outras inadequaçōes $(16 \%)$ também foram consideradas nessa categoria, pois demonstraram atitude de reflexão e julgamento. Diferentemente das respostas anteriores, o aluno não exemplificou explicitamente os movimentos inadequados, mas ressaltou suas dificuldades em relação a ela, como relata A7 na aula de atividades rítmicas: "no momento atual, 
para mim, foi cansativa, mas em condições normais de saúde é adequada". Sua fala aponta o reconhecimento de que suas limitaçôes foram decorrentes de um evento transitório pessoal, considerando-se que ela se encontrava em tratamento rigoroso de saúde.

$\mathrm{Na}$ aula de dança circular houve respostas que indicaram o momento em que o desconforto foi gerado em algumas alunas. As respostas de A1 e A11 indicaram os movimentos de giro como provocadores de tontura: "foi bom, mas me ativou a labirintite, acho que não devo fazer" (A1) e "na dança, logo no começo fiquei um pouco tonta, mas logo passou" (A11). Suas respostas, somadas às observações da aula sugerem que a quantidade de movimentos de giro tenha sido excessiva para elas, ou, como apontou A12, pode ser que a alta velocidade do movimento tenha sido o elemento que dificultou sua execução: “Todos (os movimentos) foram bons, não consigo fazer rápido, mas tento". Segundo SPIDURSO (1995), em tarefa que requer coordenação, os idosos escolhem a precisão do movimento ao invés de sua velocidade. A autora afirma que uma das principais mudanças nos idosos é o aumento da dificuldade em focar a atenção na tarefa e aponta como estratégia a sua simplificação, dividindo-a em componentes e executando-os um de cada vez.

Um aspecto a ser destacado é o nível de escolarização dos alunos, pois, diferentemente da questão anterior, a escolaridade parece não estar associada ao reconhecimento das inadequaçóes. Apesar de A12 não ter sido escolarizada, $57 \%$ de suas respostas indicaram o reconhecimento de inadequaçóes. Vale ressaltar que, tanto na questão referente a essa categoria como na anterior, a aluna foi auxiliada pelas professoras na leitura das questôes, redação das respostas e, principalmente, para a ressignificação conceitual. Como afirma GARRIDO (2001), esse é o papel fundamental do mediador ao estabelecer analogias entre a linguagem formal do questionário e informal da aluna. Para que esse procedimento seja eficaz, convém ressaltar a necessidade do professor manter-se o mais neutro possível para evitar a interferências que induzam a resposta correta.

É curioso notar que houve respostas que não afirmaram categoricamente a presença de movimentos inadequados, pois, em geral, diziam que "foi bom". Isso fica evidenciado quando se verifica que apenas duas alunas demonstraram explicitamente sua insatisfação com a aula. Uma delas é A18 que, na aula orientada por vídeo, apontou não só "muitos (movimentos inadequados) durante toda a aula", como expressou seu descontentamento pelo modo de tratamento infantilizado com que a professora se dirigia ao público alvo, no presente caso, aos idosos.
Tal fato a fez recusar-se a continuar participando da atividade, pois o vídeo mostrava uma concepção de envelhecimento e velhice vinculados à ideia de incapacidade, evidenciada, por exemplo, pelas atividades aeróbias realizadas na posição sentada numa cadeira.

Segundo Neri (2000), o preconceito é decorrente da falta de conhecimento das evidências de que nem todos os idosos são incapazes, visto que muitos velhos podem manter altos padróes de desempenho físico e cognitivo por toda sua vida. Para ОкUMA (1998), aо tratar os idosos com excessivo zelo, além do necessário para se sentirem seguros ou ainda com sentimento de compaixão ou condescendência, desconsideram-se as vivências pessoais, fazendo-os sentir-se desrespeitados em sua identidade pessoal ao serem tratados como crianças que requerem cuidados por não saber se cuidar, como são tratados por várias pessoas, inclusive profissionais.

As respostas dessa subcategoria evidenciaram um julgamento negativo das atividades e certa insatisfação em algumas aulas. Segundo Morais (2000), essa é uma das possibilidades da atitude crítica: avaliar que a situação é inconsistente, imprópria ou inaceitável, apontando as razões das percepções que levam a ver tais negatividades. A outra possibilidade apontada pelo autor é a sensata aplicação de critérios lógicos e aceitos, observando se a situação é positiva e elogiando-a. A seguir será analisado se esses critérios estão presentes nas respostas em que os alunos não reconheceram inadequaçóes nas atividades realizadas.

\section{Alunos que não reconheceram inadequações nas atividades realizadas}

Dos 61\% de respostas incluídas nesta sub-categoria, $52 \%$ estavam em branco ou continham apenas "não" (não houve movimento inadequado), indicando que, possivelmente, os alunos não reconheciam movimentos inadequados ou tinham dificuldade em expressar seus conhecimentos, como expôs A1: "não consigo me expressar".

Uma possível explicação para que a maioria dos alunos não reconhecesse movimentos inadequados é a falta de relação entre os conteúdos ensinados no PAAF e as atividades propostas pelos professores convidados. Mirás (1997) afirma que nem sempre o aluno tem presente o conhecimento prévio para essa relação. Portanto, cabe ao professor resgatar os conhecimentos sobre as possíveis inadequações de postura e prescrição do exercício para relacioná-las às novas experiências vivenciadas nas aulas. Discutir com o grupo o porquê da resposta errada é outra forma de trabalho que contribui para que o aluno reveja suas 
estratégias, localize seu erro e reorganize os dados em busca de uma solução correta (SMOLE, 2001).

Apenas $8 \%$ das respostas indicam que os alunos realizaram todas as atividades propostas na aula sem questioná-las quanto à sua adequação, demonstrando atitude de aceitação. A resposta dos alunos A15 e A17, após a aula de dança circular, representam bem essa atitude de aceitação: "Não, tudo ok" e "Não, foi tudo jóia”. À primeira vista, tal avaliação parece ser positiva, pois poderia indicar ausência de movimentos inadequados presentes nas aulas. Porém, o seu acompanhamento pela pesquisadora permitiu levantar alguns movimentos que, se realizados consecutivamente, podem causar danos às articulações, sobretudo, na execução de exercícios com coluna flexionada ou com sua rotação brusca. A incapacidade de reconhecer as inadequaçóes pode levar a um comportamento de aceitação por parte do idoso, de tudo o que o professor oferece, como ilustrado pela fala de A10: "todos os movimentos foram adequados", quando executou vários movimentos com rotação brusca da coluna, na aula de aerobox.

Como aponta SARABIA (1998), a capacidade de julgar requer uma compreensão consciente que, numa situação concreta, nem sempre é exaustiva, correta ou adequada. A avaliação e atitude positiva ou negativa em relação à atividade física nas aulas experienciadas pelos idosos podem ser decorrentes de outros fatores, além da adequada execução dos movimentos ou prescrição. Entre eles, Pizzolato (1995) menciona a empatia com o professor como um elemento importante do processo de ensino e aprendizagem dos idosos.

Embora não tenha sido intuito desse estudo comparar as respostas entre homens e mulheres, os resultados apontaram um comportamento diferente entre os gêneros. Analisando as características dos alunos, verifica-se que nenhum dos homens reconheceu inadequações na maior parte de suas respostas. Isso pode ser explicado pela boa condição física e baixa incidência de patologias nesses alunos, visto que um deles não tinha doença, outro tinha apenas uma e os dois restantes tinham duas, sendo que nenhuma dessas doenças restringia a execução de movimento.

Não perceber a inadequação dos movimentos aumenta o risco de lesões, pois mesmo que os alunos não sintam o efeito negativo imediato das atividades, elas podem ser prejudiciais quando repetidas sistematicamente. É primordial que o professor os alerte para tal possibilidade, mostrando, na correção das tarefas de cada aula, as inadequaçóes quanto à execução ou prescrição de treinamento.

Convém ressaltar que os alunos do PAAF apresentavam grande heterogeneidade no grau de escolarização, mas, provavelmente, aqueles que tiveram acesso à educação formal viveram o ensino tradicional, em que o aluno é mero receptor de conhecimento (Coll, 1998). É possível que essa seja uma barreira para a atitude crítica dos alunos, na medida em que consideram o professor como detentor do conhecimento correto, cabendo ao aluno, aceitá-lo e jamais questionálo. É desafio do PAAF superar essa crença de modo que o aluno, além do professor, assumam um papel ativo no processo de ensino e aprendizagem para que seja uma construção compartilhada.

Com base na análise das tarefas verifica-se que alguns alunos refletiram sobre suas necessidades pessoais considerando suas preferências e percepções subjetivas e reconhecem inadequações na aula. Porém, o que ficou mais evidente foi a dificuldade que eles apresentaram para responder as tarefas, visto que em grande parte elas não indicavam a presença de reflexão das necessidades pessoais (57\%) ou reconhecimento de inadequações (61\%). Provavelmente, um fator que limitou a avaliação da atitude crítica foi o procedimento da escrita, visto que a fluência nesse tipo de linguagem não é de domínio de todos os alunos, principalmente dos menos escolarizados.

Fica evidente o grande desafio para os profissionais que atuam com idosos de criar estratégias de ensino e avaliação para uma população tão heterogênea. Uma opção de estratégia de avaliação é a observação sistematizada do comportamento manifesto pelos alunos ou da discussão em grupo após a aula, pois durante a experiência no processo de ensino e aprendizagem da atitude crítica no PAAF pôde ser observado, mas não de forma sistematizada, outras demonstrações de atitude crítica que permearam a tarefa escrita.

Como estratégia de ensino, a tarefa mostrou-se positiva por possibilitar momentos de reflexão sobre a prática da atividade física após a aula. Ela permitiu verificar a capacidade dos alunos em expressar seus conhecimentos através de argumentos, percepçôes e preferências. A necessidade dos idosos em externar suas emoções e problemas pessoais já foi apontada no estudo de Pizzolato (1995), mas fica evidente a diversidade de possibilidades quando é dada oportunidade a eles de se posicionarem.

Apesar das limitações da tarefa como recurso didático, pode-se concluir que o processo de aprendizagem da atitude crítica para os idosos é possível. Esse é o outro desafio dos programas educacionais com essa população, de modo que possam superar diversos paradigmas e estereótipos em torno da aprendizagem de pessoas idosas. Como apontou FARINATTI (2000), entender que os idosos 
têm o direito de realizar suas aspirações e satisfazer suas necessidades potencializa a autonomia individual e coletiva e a sua cidadania é respeitada. E será através da educação que o idoso aprenderá a exercê-la, sabendo o que quer, o que pensa e o que sente para atuar segundo sua própria vontade (LIMA, 2001).

\begin{abstract}
Critical attitude of elderly adults to physical activity

The aim of this study was to analyze the critical attitude of elderly people in the Physical Activity Autonomy Program in relation to physical activity. The study included eighteen subjects, who answered two questions after attending each of the following classes: rhythmical activity, yoga, circular dance, tai chi chuan, saloon dance, aerobox and video oriented elderly activities. Qualitative analysis resulted in two categories of answers: reflections on personal needs and recognition of inadequacies in the proposed activities. Of these responses, $43 \%$ indicate critical reflection and 37\% indicate inadequacies. The results indicate that most of the answers show no critical attitude to class experiences. However, a limitation of this study was the student's difficult in writing procedure. This indicates a need to create other strategies to evaluation elderly population that is heterogeneous in terms of educational level and life experiences.
\end{abstract}

UnITERMS: Physical activity autonomy; Elderly; Life-long learning.

\title{
Resumen
}

Actitud crítica de la actividad física en personas mayores

El objetivo de este estudio fue analizar la actitud crítica hacia la actividad física de personas mayores del Programa Autonomía para la Actividad Física. En el estudio participaron 18 sujetos que respondieron a dos preguntas abiertas después de frecuentar las siguientes clases: actividad rítmica, yoga, danza circular, tai chi, bailes de salón, aerobox y actividades dirigidas para las personas mayores por medio de video. El análisis cualitativo resultó en dos categorías de respuestas: reflexiones sobre las necesidades personales y el reconocimiento de inadecuaciones en las actividades propuestas. De esas respuestas, el $43 \%$ indica reflexión crítica y el $37 \%$ apunta inadecuaciones. Los resultados sugieren que la mayoría de las respuestas no muestra ninguna actitud crítica a las clases asistidas. Sin embargo, una las limitaciones de este estudio fue la dificultad de escritura de los estudiantes.

Palabras clave: Autonomía para la actividad física; Personas mayores; La educación permanente.

\section{Referências}

AKIMA, H.; KANO, Y.E.; NOMOTO, Y.; ISHIZU, M.; OKADA, M.; OISHI, Y.; KATSUTA, S.; KUNA, S. Muscle function in 164 men and women aged 20-84 yr. Medicine \& Science in Sports \& Exercise, Hagerston, v.31, n.2, p. 220-26, 2001. ANDREOTTI, M.C. Fatores que influenciam a adesão de idosos de um programa de educação física supervisionado. 2001. Dissertação (Mestrado) - Escola de Educação Física e Esporte, Universidade de São Paulo, São Paulo, 2001. ANDREOTTI, M.C.; OKUMA, S.S. Perfil sócio-demográfico e de adesão inicial de idosos ingressantes em um programa de educação física. Revista Paulista de Educação Física, São Paulo, v.17, n.2, p.142-53, 2003.

BALTES, P.B. Theoretical propositions of life-span developmental psychology: on the dynamics between growth and decline. Developmental Psychology, Washington, v.5, p. 611-26, 1987. 
BALTES, P.B.; BALTES, M.M. Psychological perspectives on successful aging: the model of selective optimization with compensation. In: BALTES, P.B.; BALTES, M.M. (Eds.). Successful aging: perspectives from the behavioral sciences. Cambridge: Cambridge University Press, 1991. p.1-34.

BOGDAN, R.; BIKLEN, S. Investigação qualitativa em educação. Porto: Editora Porto, 1997.

BRANDON, L.J.; BOYETTE, L.W.; GAASCH, D.A.; LLOYD, A. Effects of strength training on functional mobility in older adults. Journal of Aging and Physical Activity, Champaign, v.8, p.214-27, 2000.

CHODZKO-ZAJKO, W.J. Physiology of aging and exercise. In: AMERICAN COUNCIL ON EXERCISE. Exercise for older adults. Champaign: Human Kinetics, 1998.

CLARCK, F.; HELLER, A.F. Peer learning: a popular model for senior education. Education Gerontology, New York, v.23, p.751-62, 1997.

COLL, C. Introdução. In: COLL, C.; POZO, J.I.; SARABIA, B.; VALLS, E. (Orgs.). Os conteúdos na reforma: ensino e aprendizagem de conceitos, procedimentos e atitudes. Porto Alegre: Artmed, 1998. p.9-16.

COLL, C.; POZO, J.I.; SARABIA, B.; VALLS, E. (Orgs.). Os conteúdos na reforma: ensino e aprendizagem de conceitos, procedimentos e atitudes. Porto Alegre: Artmed, 1998.

DENNEY, N.W. Critical thinking during the adult year: has the developmental function changed over the last four decades? Experimental Aging Research, Philadelphia, v.21, p.191-207, 1995.

ECCLESTONE, N.A.; MYERS, A.M. PATERSON, D.H. Tracking older participants of twelve physical Activity classes over a three-year period. Journal of Aging and Physical Activity, Champaign, v.6, p.70-82, 1998.

ECHEVERRY, L.G.J.; TABORDA, E.G.; GÓMEZ, M.P.Z. El baile de salón como ejercicio físico en los ancianos que asisten a la Caja de Compensación Familiar de la ciudad de Manizales. Apunts: Educación física y desportes, Barcelona, v. 67, p.82-87, 2002. FARIA JUNIOR, A. Ensino e educação para o idoso. 2000. Tese (Concurso para titular) - Faculdade de Educação, Universidade do Estado do Rio de Janeiro, Rio de Janeiro, 2000.

FARINATTI, P.T.V. Atividade física, envelhecimento e qualidade de vida. In: SEMINÁRIO INTERNACIONAL SOBRE ATIVIDADES FÍSICAS PARA A TERCEIRA IDADE: educação física e envelhecimento, perspectivas e desafios, 5., São Paulo, 2002. Anais... São Paulo: EEFEUSP, 2002. p.79-86.

. Autonomia referenciada à saúde: modelos e definições. Motus Corporis, Rio de Janeiro, v.7, n.1, p.9-45, 2000.

FREIRE, P. Pedagogia da autonomia: saberes necessários à prática educativa. São Paulo: Paz e Terra, 1996.

FREIRE, S.A.; SOMMERHALDER, C. Envelhecer nos tempos modernos. In: NERI,A.L. (Org.). E por falar em boa velhice. Campinas: Papirus, 2000.

GARRIDO, E. Sala de aula: espaço de construção de conhecimento para o aluno e de pesquisa e desenvolvimento profissional para o professor. In: CASTRO, A.D.; CARVALHO, A.M.P. (Orgs.). Ensinar a ensinar. São Paulo: Pioneira/Thomson Learning, 2001. GUIDO, M.; LIMA, R.M.; BENFORD, R.; LEITE, T.K.M.; PEREIRA, R.W.; OLIVEIRA, R.J. Efeitos de 24 semanas de treinamento resistido sobre índices da aptidão aeróbia de mulheres idosas. Revista Brasileira de Medicina do Esporte, Niterói, v.16, n.4, p.259-63, 2010.

JONES, B.D.; BAYEN, U.J. Teaching older adults to use computers: recommendations based on cognitive aging research. Education Gerontology, New York, v.24, p.675-89, 1998.

LIMA, M.P. Gerontologia educacional. Revista Kairós, São Paulo, v.4, p.109-121, 2001.

McMURDO, M.E.T. Exercise in old age: time to unwrap the cotton wool. British Journal Sports Medicine, London, v.33, p. 295-300, 1999.

MIRÁS, M. Um ponto de partida para a aprendizagem de novos conteúdos: os conhecimentos prévios. In: COLL, C. (Org.) O construtivismo em sala de aula. São Paulo: Ática, 1997.

MORAIS, J.F.R. A criticidade como fundamento do humano. In: VEIGA, V.P.A.; CASTANHO, M.E.L.M. (Orgs.)

Pedagogia universitária: a aula em foco. Campinas: Papirus, 2000.

MOURA, M.P. A organização conceitual em adultos pouco escolarizados. In: OLIVEIRA, M.B.; OLIVEIRA, M.K. (Orgs.). Investigaçóes cognitivas, conceitos, linguagem e cultura. Porto Alegre: Artes Médicas Sul, 1999.

NERI, A.L. Apresentação: qual é a idade da velhice? In: . (Org.). E por falar em boa velhice. Campinas: Papirus, 2000.

OKUMA, S.S. O idoso e a atividade física. Campinas: Papirus, 1998.

. Cuidado com o corpo: uma pedagogia para a sua ativação. In: FREITAS,E. et al. (Orgs.). Tratado de geriatria e gerontologia. Rio de Janeiro: Guanabara Koogan, 2002.

ORGANIZAÇÃO MUNDIAL DA SAÚDE (OMS). Carta de Ottawa, 1986. In: BRASIL. Ministério da Saúde. Promoção da saúde. Brasília: MS, 2001.

Declaração de Jacarta, 1997. In: BRASIL. Ministério da Saúde. Promoção da saúde. Brasília: MS, 2001.

728 • Rev. bras. Educ. Fís. Esporte, São Paulo, v.26, n.4, p.717-29, out./dez. 2012 
Rede de megapaíses, 1998. BRASIL. Ministério da Saúde. Promoção da saúde. Brasília: MS, 2001.

O’NEILL, D.E.T.; THAYER, R.E.; TAYLOR, A.W.; DZIALOSZYNSKI, T.M.; NOBLE, E.G. Effects of short-term resistance training on muscle strength and morphology in the elderly. Journal of Aging and Physical Activity, Champaign, v.8, p.312-24, 2000. PIZZOLATO, C.E. Características da construção do processo de ensino e aprendizagem da língua estrangeira (inglês) com adultos da $3^{\text {a }}$ idade. 1995. Dissertação (Mestrado) - Faculdade de Educação, Universidade Estadual de Campinas, Campinas, 1995. RESNICK, B. Prescribing an exercise program and motivating older adults to comply. Educational Gerontology, New York, v.27, p.209-26, 2001.

SANTOS DE SÁ, M.A.A. O idoso e o computador: condições facilitadoras e dificultadoras para o aprendizado. 1999. Dissertação (Mestrado) - Faculdade de Educação, Pontifícia Universidade Católica, São Paulo, 1999.

SARABIA, B. A aprendizagem e o ensino das atitudes. In: COLL, C.; POZO, J.I.; SARABIA, B.; VALS, E. Os conteúdos na reforma: o ensino e aprendizagem de conceitos, procedimentos e atitudes. Porto Alegre: Artes Médicas, 1998.

SCULLY, D.; KREMER, J.; MEADE, M.M.; GRAHAM, R.; DUDGEON, K. Physical exercise and psychological well being: a critical review. British Journal Sports Medicine, London, v.32, p.111-20, 1998.

SEEDHOUSE, D.; CRIBB, A. Introduction. In: SEEDHOUSE, D.; CRIBB, A. (Eds.). Changing ideas in health care. Chichester: John Wiley \& Sons, 1989. p.1-7.

SMOLE, K.C.S. Inteligência e avaliação: da idéia de medida à idéia de projeto. 2001. Tese (Doutorado) - Faculdade de Educação, Universidade de São Paulo, São Paulo, 2001.

SOLÉ, I.; COLL, C. Os professores e a concepção construtivista. In: COLL, C. (Org.). O construtivismo em sala de aula. São Paulo: Ática, 1997.

SPIDURSO, W.W. Coordination and skill in complex movements. In: SPIDURSO, W.W. Physical dimensions of aging. Champaign: Human Kinetics, 1995.

SPIGNER-LITTLES, D.; ANDERSON, C.E. Constructivism: a paradigm for older learners. Educational Gerontology, New York, v.25, p.203-09, 1999.

STROM, R.; STROM, S.; FOURNET, L.; STROM, P. Cooperative learning in old age: instruction and assessment. Education Gerontology, New York, v.23, p.581-99, 1997.

TAKKINEN, S.; SUUTAMA, T.; RUOPPILA, I. More meaning by exercising? Physical activity as a predictor of a sense of meaning in life and of self-rated health and functioning in older age. Journal of Aging and Physical Activity, Champaign, v.9, p.128-41, 2001. TEIXEIRA, D.C. Efeitos de uma intervenção específica sobre idosos na formação de atitudes de futuros profissionais de educação física em relação ao velho e à velhice. 2003. Dissertação (Mestrado) - Escola de Educação Física e Esporte, Universidade de São Paulo, São Paulo, 2003.

TWITCHELL, S.; CHERRY, K.E.; TROTT, J.W. Educational strategies for older learners: suggestions from cognitive aging. Education Gerontology, New York, v.27, p.209-26, 1996.

VELARDI, M. Pesquisa e ação em educação física para idosos. 2003. Tese (Doutorado) - Faculdade de Educação Física, Universidade Estadual de Campinas, Campinas, 2003.

WHALEY, D.R.; EBBECK, V. Older adults' classes constraints to participation in structured exercise. Journal of Aging and Physical Activity, Champaign, v.5, n.3, p.190-212, 1997.

ZABALA, A. A prática educativa: como ensinar. Porto Alegre: ArtMed, 1998.

\section{Agradecimentos}

As autoras agradecem o apoio financeiro concedido pela CAPES através da bolsa de mestrado.

\begin{tabular}{r|l} 
ENDEREÇo & \\
Tiemi Okimura-Kerr & \\
Raposo Tavares, 3175 & Recebido para publicação: 23/08/2011 \\
Rão Paulo - SP - BRASIL & Aceito: 25/05/2012
\end{tabular}

05577-100 - São Paulo - SP - BRASIL e-mail: tiemiok@yahoo.com

Revisado: 14/05/2012

Rev. bras. Educ. Fís. Esporte, São Paulo, v.26, n.4, p.717-29, out./dez. 2012 • 729 